\title{
InGaN/GaN multiple quantum well solar cells with long operating wavelengths
}

\author{
R. Dahal, ${ }^{1,2}$ B. Pantha, ${ }^{1,2}$ J. Li, ${ }^{1}$ J. Y. Lin, ${ }^{1}$ and H. X. Jiang ${ }^{1, a)}$ \\ ${ }^{1}$ Department of Electrical and Computer Engineering and Nano-Tech Center, Texas Tech University, \\ Lubbock, Texas 79409, USA \\ ${ }^{2}$ Department of Physics, Kansas State University, Manhattan, Kansas 66506-2601, USA
}

(Received 9 December 2008; accepted 20 January 2009; published online 10 February 2009)

\begin{abstract}
We report on the fabrication and photovoltaic characteristics of InGaN solar cells by exploiting InGaN/GaN multiple quantum wells (MQWs) with In contents exceeding 0.3, attempting to alleviate to a certain degree the phase separation issue and demonstrate solar cell operation at wavelengths longer than previous attainments $(>420 \mathrm{~nm})$. The fabricated solar cells based on $\mathrm{In}_{0.3} \mathrm{Ga}_{0.7} \mathrm{~N} / \mathrm{GaN}$ MQWs exhibit an open circuit voltage of about $2 \mathrm{~V}$, fill factor of about $60 \%$, and an external efficiency of $40 \%(10 \%)$ at $420 \mathrm{~nm}(450 \mathrm{~nm})$. () 2009 American Institute of Physics.
\end{abstract} [DOI: $10.1063 / 1.3081123$ ]

InGaN alloys have been widely exploited as active materials for light-emitting diodes (LEDs) and laser diodes with emission wavelengths covering from near UV to green spectral regions. ${ }^{1-6}$ InGaN alloys recently emerge as a new solar cell materials system due to their tunable energy band gaps (varying from $0.7 \mathrm{eV}$ for $\mathrm{InN}$ to $3.4 \mathrm{eV}$ for $\mathrm{GaN}$, covering almost the whole solar spectrum) and superior photovoltaic characteristics (direct energy band gap in the entire alloy range and high carrier mobility, drift velocity, radiation resistance, and optical absorption of $\sim 10^{5} \mathrm{~cm}^{-1}$ near the band edge). ${ }^{7-11}$

Although InGaN based solar cells offer tremendous potential for terrestrial as well as space photovoltaic applications, there are only a few reports on InGaN based solar cells. Furthermore, most reported InGaN solar cells have In contents lower than $15 \%$ and band gaps near $3 \mathrm{eV}$, or larger, and therefore deliver diminishing quantum efficiency at wavelengths longer than $420 \mathrm{~nm}^{7-11}$ An earlier theoretical calculation has indicated that the requirements of an active material system to obtain solar cells having a solar energy conversion efficiency greater than $50 \%$ can be fulfilled by InGaN alloys with In content of about $40 \%{ }^{12}$ Additionally, III-nitride multijunction solar cells with near ideal band gaps for maximum solar energy conversion efficiency must incorporate InGaN layers with higher In contents or lower energy band gaps.

However, the realization of high crystalline quality InGaN films in the entire composition range is highly challenging. One of the biggest problems is attributed to the large lattice mismatch between $\mathrm{InN}$ and $\mathrm{GaN}$, resulting in low solubility and phase separation. ${ }^{13,14}$ Recently, we have shown that by directly depositing on GaN or AlN epitemplates without buffer layers, single phase InGaN epilayers across the entire alloy range could be produced by metal organic chemical vapor deposition (MOCVD) ${ }^{15}$ This fact is illustrated in Fig. 1(a), where x-ray diffraction (XRD) data for $\theta-2 \theta$ scans of the (002) plane for several representative $\mathrm{In}_{x} \mathrm{Ga}_{1-x} \mathrm{~N}$ epilayers (200 nm thick) are shown. All curves scanned down to the InN peak position exhibit no multiple peaks, implying that our $\operatorname{In}_{x} \mathrm{Ga}_{1-x} \mathrm{~N}$ epilayers are not phase

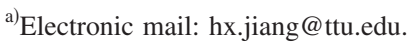

separated. The results represent a significant advancement of MOCVD growth of InGaN alloys. However, the film homogeneity is still poor in the middle composition range. The full width at half maximum of the rocking curves of $\omega$-scans of the (002) reflection increases from around 1000 arc sec at $x \sim 0.2$ to about 3000 arc sec at $x \sim 0.5$ for films of about $0.2 \mu \mathrm{m}$ in thickness. ${ }^{15}$ The photoluminescence (PL) emission properties of $\operatorname{In}_{x} \mathrm{Ga}_{1-x} \mathrm{~N}$ epilayers also deteriorate with an increase in $x$. For instance, as shown in Fig. 1(b), the overall PL emission intensity of $\operatorname{In}_{0.4} \mathrm{Ga}_{0.6} \mathrm{~N}$ films is about 100 times lower than that of $\operatorname{In}_{0.2} \mathrm{Ga}_{0.8} \mathrm{~N}$. This trend of reduced crystalline quality with increasing $x$ makes the realization of solar cells based on $\operatorname{In}_{x} \mathrm{Ga}_{1-x} \mathrm{~N}$ with $x>0.25$ highly challenging. Evidence that strain could suppress phase separation in $\mathrm{InGaN}$ has been reported by various groups. It was shown that InGaN alloys across the entire composition range without phase separation can be grown when the layer is embedded within an InGaN/GaN double heterostructure. ${ }^{16,17}$ In this letter, we report on the fabrication and characterization of InGaN solar cells by exploiting $\mathrm{In}_{x} \mathrm{Ga}_{1-x} \mathrm{~N} / \mathrm{GaN}$ multiple quantum wells (MQWs) with the attempt to alleviate to a certain degree the phase separation issue and demonstrate solar cell operation in wavelengths longer than that of previous attainments.
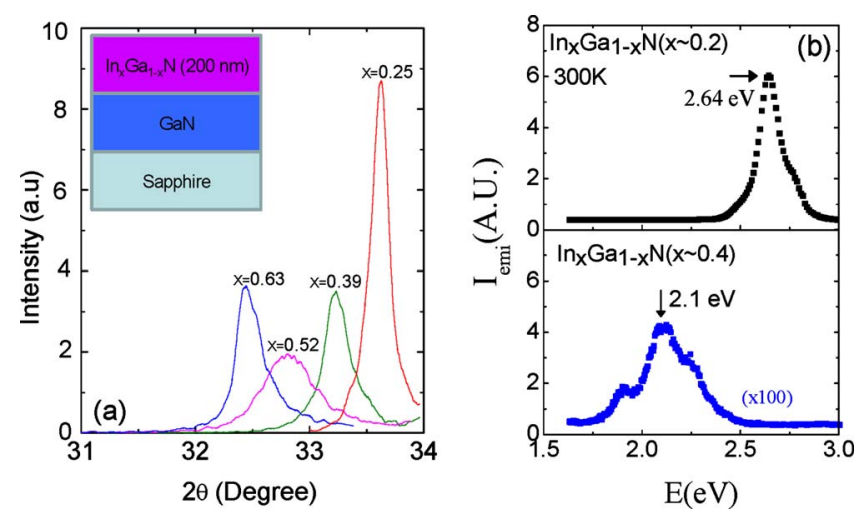

FIG. 1. (Color online) (a) XRD $\theta-2 \theta$ curves of (002) planes (b) PL emission spectra of representative $\operatorname{In}_{x} \mathrm{Ga}_{1-x} \mathrm{~N}$ epilayers $(0.2 \mu \mathrm{m}$ thick $)$ grown on epi-GaN/ $\mathrm{Al}_{2} \mathrm{O}_{3}$ templates. 

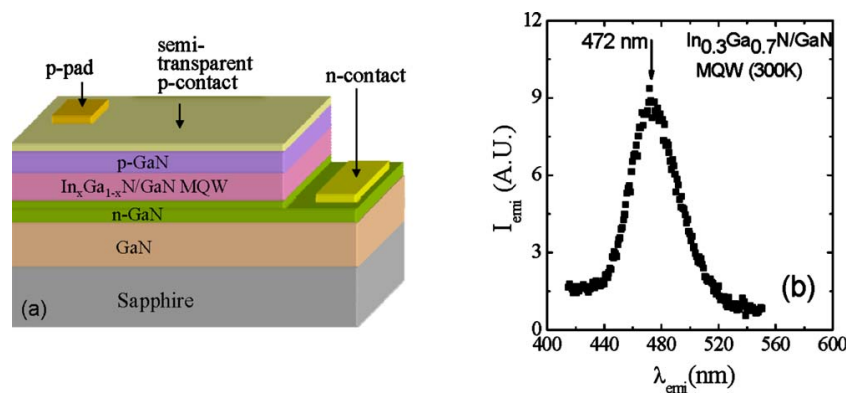

FIG. 2. (Color online) (a) Schematic layer structure of solar cells based on InGaN/GaN MQWs. (b) PL emission spectrum of an $\operatorname{In}_{x} \mathrm{Ga}_{1-x} \mathrm{~N} / \mathrm{GaN}$ MQW $(x \sim 0.3)$ solar cell structure.

The solar cell layer structure is shown in Fig. 2(a), and the light absorbing region consists of eight periods of $\mathrm{In}_{x} \mathrm{Ga}_{1-x} \mathrm{~N}(3 \mathrm{~nm}) / \mathrm{GaN}(8 \mathrm{~nm})$ MQWs. The MQWs were grown under the established MOCVD growth conditions of $\mathrm{In}_{x} \mathrm{Ga}_{1-x} \mathrm{~N}$ epilayers ${ }^{15}$ with targeted $x$ values of 0.3 and 0.4 with the aim of obtaining photovoltaic responses in longer operating wavelengths than previous demonstrations. ${ }^{7-11}$ The PL spectrum for an $\operatorname{In}_{x} \mathrm{Ga}_{1-x} \mathrm{~N} / \mathrm{GaN}$ MQW solar cell structure with the targeted In content of 0.3 is shown in Fig. 2(b) and exhibits an emission line around $472 \mathrm{~nm}$ (or $\sim 2.63 \mathrm{eV}$ ). The thickness of $p$-GaN $(n-\mathrm{GaN})$ is $\sim 150 \mathrm{~nm}(\sim 0.5 \mu \mathrm{m})$. The device structure was grown on a $\mathrm{GaN}$ epilayer (3 $\mu \mathrm{m}) /$ sapphire template. As a quick demonstration, we adopted the device fabrication steps of commercial III-nitride LEDs by implementing a thin Ni/Au $(2 / 6 \mathrm{~nm})$ semitransparent current spreading layer to minimize the $p$-contact resistance on the $p-\mathrm{GaN}$ window. An optical microscopy image of a fabricated InGaN/GaN MQW solar cell is shown in the inset of Fig. 3(a). The devices were characterized using a microprobe station with a source meter (Keithley 2400). For current- and power-density versus voltage characteristics measurements, the solar cell was illuminated by a white light source (with no optical filters), which has an emission spectrum, as shown in Fig. 3(a). For quantum efficiency versus excitation wavelength characterization, monochromatic illumination was obtained by using the same white light source in conjunction with a monochromator (with a spectral resolution of about $2.5 \mathrm{~nm}$ ).

Current versus voltage $(I-V)$ characteristics of two fabricated $\operatorname{In}_{x} \mathrm{Ga}_{1-x} \mathrm{~N} / \mathrm{GaN}$ MQW solar cells with targeted In contents $(x)$ of about 0.3 and 0.4 in the well region are shown in Fig. 3(b). The open-circuit voltages $\left(V_{\mathrm{oc}}\right)$ for de-
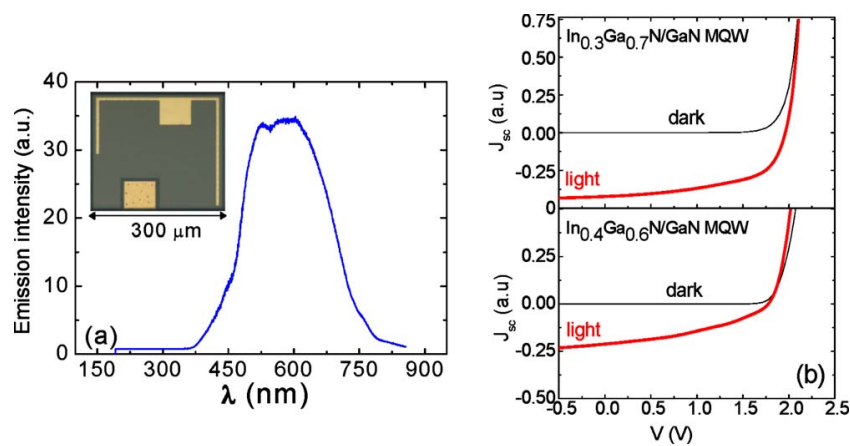

FIG. 3. (Color online) (a) Emission spectrum of the white light source used for current-voltage $(I-V)$ characteristics measurements and the inset is an optical microscopy image of a fabricated device. (b) $I-V$ characteristics $\mathrm{In}_{x} \mathrm{Ga}_{1-x} \mathrm{~N} / \mathrm{GaN}$ MQW ( $x \sim 0.3$ and 0.4$)$ solar cells.
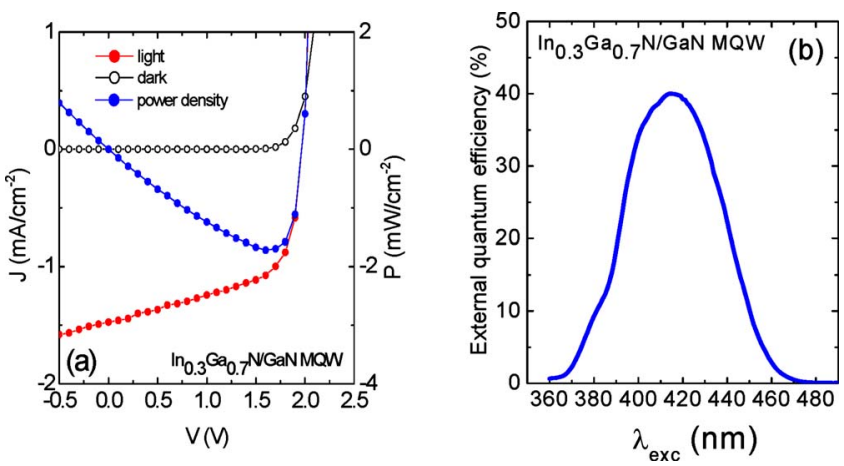

FIG. 4. (Color online) (a) Current- and power-density vs voltage characteristics for a solar cell with $\operatorname{In}_{x} \mathrm{Ga}_{1-x} \mathrm{~N} / \mathrm{GaN}$ MQW $(x \sim 0.3)$ as the active region. (b) External quantum efficiency vs excitation wavelength for the same device.

vices with $x \sim 0.3$ and 0.4 are about 2.0 and $1.8 \mathrm{~V}$, respectively. These values are in reasonable agreement with the band gaps of $\operatorname{In}_{0.3} \mathrm{Ga}_{0.7} \mathrm{~N}$ and $\mathrm{In}_{0.4} \mathrm{Ga}_{0.6} \mathrm{~N}$. However, the performance of the lower energy gap device (with $\mathrm{In}_{0.4} \mathrm{Ga}_{0.6} \mathrm{~N} / \mathrm{GaN}$ MQWs as active region) is much poorer than that of the higher energy band gap device (with $\mathrm{In}_{0.3} \mathrm{Ga}_{0.7} \mathrm{~N} / \mathrm{GaN}$ MQWs as active region), despite the fact that $\mathrm{In}_{0.4} \mathrm{Ga}_{0.6} \mathrm{~N} / \mathrm{GaN}$ MQWs are expected to have a much better spectral overlap with the excitation source. This degradation in solar cell performance corroborates the XRD and PL results illustrated in Fig. 1 and is a direct consequence of reduced material quality with increasing $x$, which leads to a higher loss of the photogenerated charge carriers. The photovoltaic characteristics observed here are also consistent with the well established fact that the quantum efficiencies of III-nitride green LEDs are much lower than those of blue LEDs.

Current- and power-density versus voltage characteristics for the higher performance device (with $\mathrm{In}_{0.3} \mathrm{Ga}_{0.7} \mathrm{~N} / \mathrm{GaN}$ MQWs as active region) are plotted in Fig. 4(a), from which a fill factor of about $60 \%$ is obtained. The quantum efficiency as a function of excitation wavelength for the same device is shown in Fig. 4(b), which demonstrates that the device delivers a quantum efficiency of $40 \%$ at $420 \mathrm{~nm}$ and $10 \%$ at $450 \mathrm{~nm}$. The response in the shorter wavelength region $(<300 \mathrm{~nm})$ is limited by the use of $p$-GaN window ${ }^{11}$ and can be improved if a larger band gap material such as $p$-AlGaN or $p$-InAlGaN is incorporated. Three major quantum efficiency limiting factors include the following: (1) Absorption in the semitransparent $p$-contact layer-current spreading $p$-contact layer was simply adopted from LED fabrication and the $p$-contact schemes need to be optimized for solar cell applications. (2) Thin light absorption layer-the optical absorption layer thickness is too thin in the present MQW structure. The well/barrier thickness and period of the MQW active region need to be optimized to maximizing light absorption but minimizing other detrimental effects due to the incorporation of relatively high In content InGaN alloys in the well region. (3) Low crystalline quality of InGaN alloys with relatively high In contentsthis remains as one of the foremost challenging issues for the nitride research community. Nevertheless, this is the first demonstration of InGaN based solar cells with good external quantum efficiencies at such long operating wavelengths, which suggest that MQW is a viable approach to design high efficiency solar cells based on InGaN with relatively high In 
contents for optimal solar energy conversion.

In summary, we report on the growth and fabrication of InGaN/GaN MQW based solar cells incorporating InN factions of $30 \%$ and $40 \%$. The devices exhibit a fill factor of about $60 \%$ and deliver an unprecedented external quantum efficiency of $40 \%$ at $420 \mathrm{~nm}$ and $10 \%$ at $450 \mathrm{~nm}$.

This materials growth effort was supported by DARPA and the device characterization effort was supported by AFOSR (Grant No FA9550-06-1-0441). H.X.J. and J.Y.L. gratefully acknowledge the support of the Edward Whitacre Endowed Chair and Linda Whitacre Endowed Chair through the AT\&T Foundation.

${ }^{1}$ S. Nakamura, M. Senoh, S. Nagahama, N. Iwasa, T. Yamada, T. Matsushita, Y. Sugimoto, and H. Kiyoku, Appl. Phys. Lett. 69, 1477 (1996).

${ }^{2}$ T. Kozaki, S. Nagahama, and T. Mukai, Proc. SPIE 6485, 648503 (2007). ${ }^{3}$ C. Skierbiszewski, P. Wiśniewski, M. Siekacz, P. Perlin, A. FeduniewiczZmuda, G. Nowak, I. Grzegory, M. Leszczyński, and S. Porowski, Appl. Phys. Lett. 88, 221108 (2006)

${ }^{4}$ H. X. Jiang, S. X. Jin, J. Li, J. Shakya, and J. Y. Lin, Appl. Phys. Lett. 78, 1303 (2001).

${ }^{5}$ M. Funato, M. Unde, Y. Kawakami, Y. Narukawa, T. Kosugi, M. Taka- nashi, and T. Mukai, Jpn. J. Appl. Phys., Part 2 45, L659 (2006).

${ }^{6}$ T. Lu, C. Kao, H. Kuo, G. Huang, and S. Wang, Appl. Phys. Lett. 92, 141102 (2008).

${ }^{7}$ O. Jani, I. Ferguson, C. Honsberg, and S. Kurtz, Appl. Phys. Lett. 91 132117 (2007).

${ }^{8}$ J. Wu, W. Walukiewich, K. M. Yu, W. Shan, J. W. Ager, E. E. Haller, H Lu, W. J. Schaff, W. K. Metzger, and S. Kurtz, J. Appl. Phys. 94, 6477 (2003).

${ }^{9}$ Y. Nanishi, Y. Satio, and T. Yamaguchi, Jpn. J. Appl. Phys., Part 1 42, 2549 (2003).

${ }^{10}$ M. Vazquez, C. Algora, I. Rey-Stolle, and J. R. Gonzalez, Progr. Photovoltaics 15, 477 (2007)

${ }^{11}$ C. J. Neufeld, N. G. Toledo, S. C. Cruz, M. Iza, S. P. DenBaars, and U. K. Mishra, Appl. Phys. Lett. 93, 143502 (2008).

${ }^{12}$ A. De Vos, Endoreversible Thermodynamics of Solar Energy Conversion (Oxford University Press, Oxford, 1992), p. 90.

${ }^{13}$ I. Ho and G. B. Stringfellow, Appl. Phys. Lett. 69, 2701 (1996).

${ }^{14}$ S. Y. Karpov, 3, 16 (1998)

${ }^{15}$ B. N. Pantha, J. Li, J. Y. Lin, and H. X. Jiang, Appl. Phys. Lett. 93, 182107 (2008).

${ }^{16}$ R. Singh, D. Doppalapudi, T. D. Moustakas, and L. T. Romano, Appl. Phys. Lett. 70, 1089 (1997).

${ }^{17}$ A. Tabata, L. K. Teles, L. M. R. Scolfaro, J. R. Leite, A. Kharchenko, T. Frey, D. J. As, D. Schikora, K. Lischka, J. Furthmuller, and F. Bechstedt, Appl. Phys. Lett. 80, 769 (2002). 